\title{
Transcriptome Changes Associated with Boron Applications in Fruits of Watercore-susceptible Pear Cultivar
}

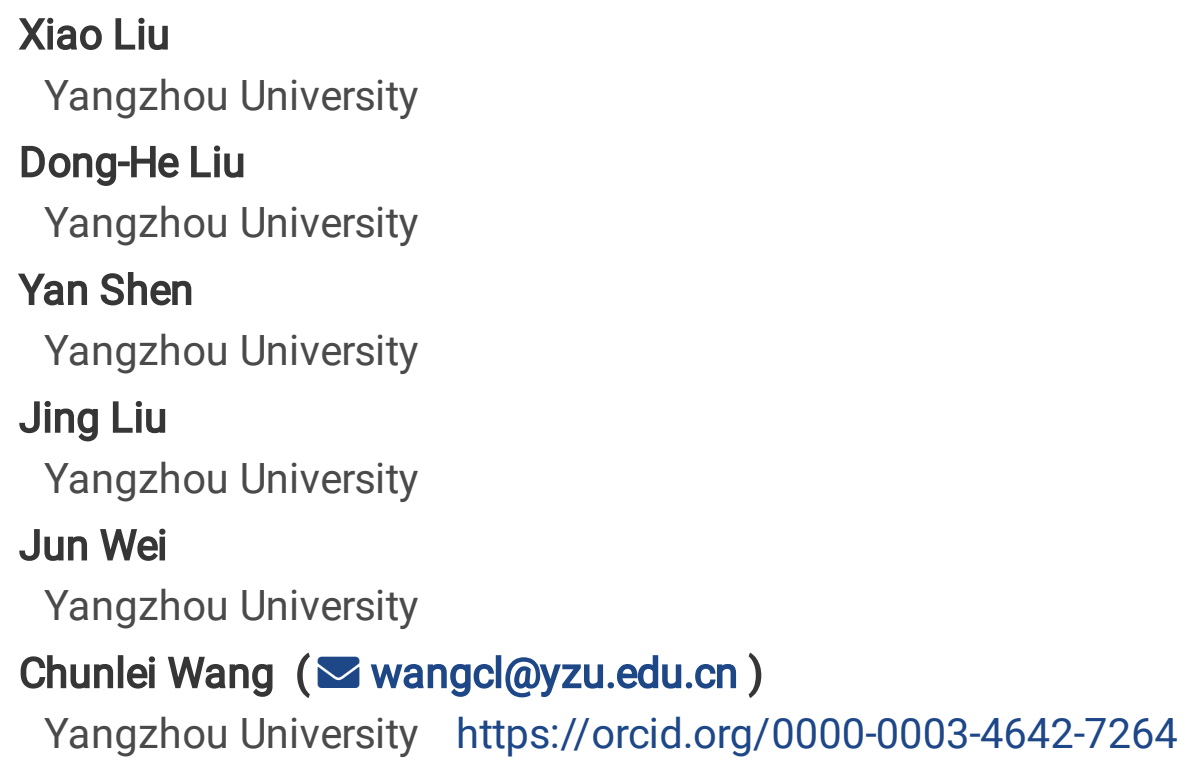

Xiao Liu

Yangzhou University

Dong-He Liu

Yangzhou University

Yan Shen

Yangzhou University

Jing Liu

Yangzhou University

Jun Wei

Yangzhou University

Chunlei Wang ( $\nabla$ wangcl@yzu.edu.cn )

Yangzhou University https://orcid.org/0000-0003-4642-7264

\section{Research Article}

Keywords: Pear, Transcriptome, Boron applications, Watercore, Fruit quality

Posted Date: September 3rd, 2021

DOI: https://doi.org/10.21203/rs.3.rs-856321/v1

License: (9) (i) This work is licensed under a Creative Commons Attribution 4.0 International License. Read Full License 


\section{Abstract}

Watercore is a common physiological disorder in pear and is closely related to excessive accumulation of sorbitol and sucrose. Our previous research found the watercore incidence of 'Akibae' (Pyrus pyrifolia cv. Akibae) fruit significantly decreased after boron application (BA). Moreover, foliar spray of boric acid also significantly improved fruit quality. To uncover the mechanisms underlying pear fruit response to $B A$, a comprehensive transcriptome analysis was performed in this study. Transcriptome results revealed a total of 3146 up-regulated and 1145 down-regulated differently expressed genes (DEGs) between control and treated fruits of 'Akibae' pear, respectively. BA significantly induced expression of sorbitol metabolism and sucrose metabolism genes. Besides, BA also increased the expression of starch degradation, fatty acid synthesis, IAA (indole-3-acetic acid) degradation, GA (gibberellin acid) synthesis and inhibit the expression of ethylene synthesis genes. Overall, these findings suggested that BA alleviated 'Akibae' watercore occurrence and improve fruit quality by regulating the decrease of sorbitol and sucrose, increased of fatty acid and a balance of plant hormone. Our results provided further information for understanding the molecular mechanism of the effect of boron application on pear fruit.

\section{Introduction}

Watercore is a physiological disorder which occurs frequently in the Rosaceae fruit and often occurs in the ripening stage of fruit ${ }^{1}$. But at present, the watercore in pear has not been paid enough attention, which often causes great economic losses. A wide range of environmental and physiological factors have been implicated in the incidence of watercore. In general, the mineral nutrition unbalance contributing to watercore incidence. A number of physiological disorders associated with low fruit calcium content can develop in the orchard or become evident after a period of storage in both apple and pear ${ }^{2}$. Besides, boron appear to have a fundamental role not only in fruit quality but also in physiological disorders, affecting basic structural features and physiological processes in plant ${ }^{3}$. 'Akibae' pear is a selfcompatible cultivar and resistant to black spot disease, however, highly susceptible to watercore ${ }^{4}$. Our previous study found boron application can reduce the occurrence of 'Akibae' pear ${ }^{5}$. However, there are few studies on the relationship between boron and watercore at molecular level.

Boron (B) plays important roles in numerous metabolic and physiological processes of higher plants, including sugar transport, cell wall synthesis and lignification, cell wall structure maintenance, carbohydrate metabolism, RNA metabolism, respiration, plant hormone metabolism, phenol metabolism, and membrane transport ${ }^{6}$. Boron applications is one of the important measures to improve fruit quality in plant production. For instance, boron application resulted in an increase in flower percentage, final fruit set, firmness of the fruit, TSS content, fruit juice ascorbic acid and fruit yield in various economic crops ${ }^{7-}$ 12. However, the transcriptional changes of fruit quality as influenced by boron applications are still rarely reported. 
Hereby, the purpose of current research was to provide important information for further functional studies of novel boron induced gene expression of 'Akibae' related to inhibit watercore occurrence and quality metabolism using RNA-Seq technology.

\section{Materials And Methods}

\section{Plant materials and treatments}

The 'Akiba' (Pyrus pyrifolia cv. Akibae) which grafted onto Pyrus calleryana in the pear orchards of the Yangzhou University, Jiangsu Province, China, were used in the present study. Pear trees were planted in double-layer trellis training and pruning and the fruit had high consistency. The 80 days after flowering (DAF) fruits were treated with the concentration of $0.1 \%$ boron acid. The control fruits were treated with purified water. Five uniform fruits of each treatment were randomly collected from the outer crown of the tree after ten days treatment and named BA (Boron Application) and CK (Control), respectively. The samples were treated with liquid nitrogen immediately and were stored at $-80^{\circ} \mathrm{C}$.

\section{RNA extraction and sequencing}

RNA of each sample was isolated using the Trizol Kit (Promega, USA) following the manufacturer's instructions. To gain insight into the transcriptomic dynamics of boron application fruit, RNA-seq analysis was performed using pulp tissues in three biological replicates. For each sample, $1 \mu \mathrm{g}$ of RNA was used to generate RNA-seq library with NEB Next ${ }^{\circledR}$ UltraTM RNA Library Prep Kit for Illumina (NEB, Ipswich, USA) and library quality was assessed on the Agilent Bioanalyzer 2100 system. The libraries were sequenced on the Illumina Novaseq platform by Novagene (Beijing, China). Raw data (raw reads) of fastq format were first processed and clean reads were obtained by removing reads containing adapter and poly-N and those of low quality. Meanwhile, Q20, Q30 and GC content of the clean data were also calculated. The high quality clean data was mapped to the reference genome of Pyrus bretschneideri Rehd ${ }^{13}$ using Hisat2. Gene expression levels were estimated with Fragments Per Kilobase of transcript sequence per Millions (FPKM). Differential expression analysis of two groups was performed using the DESeq2 R package, and $P$-values were adjusted using the Benjamini and Hochberg's approach for controlling the false discovery rate. The differentially expressed genes (DEGs) were

screened according to the following criteria: $\log _{2}$ foldchange $\mid \geq 1$ and corrected $P<0.05$. The selected DEGs were also annotated with the Gene Ontology (GO) and Kyoto Encyclopedia of Genes and Genomes (KEGG).

\section{Results}

\section{RNA sequencing and analysis of differentially expressed genes}


The transcriptome changes of BA pulp were investigated through RNA-Seq analysis. More than 40 million reads were generated per sample. Of these reads, the Q30 percentage (sequencing error rate $<1 \%$ ) was over $93 \%$, and GC content was approximately $47 \%$ for the libraries. Among all the libraries, $64.85-66.32 \%$ of unique reads were mapped to the Pyrus bretschneideri Rehd (Table 1).

\begin{tabular}{|lllll|}
\hline \multicolumn{5}{c|}{ Table 1 } \\
\hline \multicolumn{5}{|c|}{ Statistics of sequencing data of the six libraries. } \\
\hline Library & Clean reads & Q30 ratio (\%) & GC content (\%) & Mapping ratio (\%) \\
\hline BA1 & 42034166 & 93.59 & 46.93 & $27270180(64.88 \%)$ \\
\hline BA2 & 44906822 & 93.64 & 46.91 & $29120166(64.85 \%)$ \\
\hline BA3 & 41265050 & 93.64 & 47.02 & $27011504(65.46 \%)$ \\
\hline CK1 & 45391358 & 93.73 & 47.11 & $30102908(66.32 \%)$ \\
\hline CK2 & 43646738 & 93.86 & 46.82 & $28547478(65.41 \%)$ \\
\hline CK3 & 42463764 & 93.6 & 46.67 & $27619994(65.04 \%)$ \\
\hline
\end{tabular}

A total of 3146 genes and 1145 genes in BA pulp were significantly up-regulated and down-regulated, respectively (Fig. 1A). All the DEGs were subjected to GO and KEGG analysis. In the GO database, thylakoid, thylakoid part, photosynthetic membrane, photosystem, et al were the most enriched in the 'cellular component' category; iron ion binding, DNA binding transcription factor activity, et al were the most enriched in the 'molecular function' category cellular component (Fig. 1B). Pathways showing significant change ( $Q$ value $\leq 0.05)$ in BA pulp were identified using the KEGG database. The DEGs were mainly involved in the pathways of plant hormone signal transduction, starch and sucrose metabolism, photosynthesis, phenylpropanoid biosynthesis, flavonoid biosynthesis, carotenoid biosynthesis, brassinosteroid biosynthesis and et al (Fig. 1 C).

\section{Changes of sugar metabolism-related gene expression in BA fruit}

Sorbitol metabolism related gene analysis showed that a sorbitol synthesis gene, S6PDH (LOC103966946), was significantly down-regulated. The expression levels of three sorbitol dehydrogenase genes (LOC103960512, LOC103930819 and LOC103930934), seven sorbitol transporter genes (LOC103936915, LOC103964420, LOC103948508, LOC103929477, LOC103936910, LOC103936324 and LOC103964421) and a starch degradation gene (LOC103934256) were significantly increased in BA fruit. Four sucrose-phosphate synthase genes (LOC103946723, LOC103937917, LOC103952486 and LOC103956574) and two sucrose synthase genes (LOC103927263 and LOC103946870) were significantly down-regulated and up-regulated after the treatment of boric acid, respectively (Table 2 ). 


\section{Table 2}

List of DEGs relate to sorbitol, sucrose and starch metabolism

ID Gene description $\quad \log _{2}$ Fold Change

Sorbitol metabolism

\begin{tabular}{lll}
\hline LOC103966946 & D-sorbitol-6-phosphate dehydrogenase, S6PDH & -1.59 \\
LOC103960512 & Sorbitol dehydrogenase, SDH & 1.34 \\
LOC103930819 & Sorbitol dehydrogenase, SDH & 1.46 \\
\hline LOC103930934 & Sorbitol dehydrogenase, SDH & 8.02 \\
\hline LOC103936915 & Sorbitol transporter, SOT & 4.67 \\
\hline LOC103964420 & Sorbitol transporter, SOT & 4.28 \\
\hline LOC103948508 & Sorbitol transporter, SOT & 5.99 \\
\hline LOC103929477 & Sorbitol transporter, SOT & 8.85 \\
\hline LOC103936910 & Sorbitol transporter, SOT & 6.96 \\
\hline LOC103936324 & Sorbitol transporter, SOT & 5.73 \\
\hline LOC103964421 & Sorbitol transporter, SOT & 4.65 \\
\hline Sucrose metabolism & & -2.29 \\
\hline LOC103946723 & Sucrose-phosphate synthase, SPS & -2.55 \\
\hline LOC103937917 & Sucrose-phosphate synthase, SPS & -3.80 \\
\hline LOC103952486 & Sucrose-phosphate synthase, SPS & -2.54 \\
\hline LOC103956574 & Sucrose-phosphate synthase, SPS & 1.25 \\
\hline LOC103927263 & Sucrose synthase, SS & 3.26 \\
\hline LOC103946870 & Sucrose synthase, SS & \\
\hline Starch degradation & & B-amylase \\
\hline LOC103934256 & & \\
\hline
\end{tabular}

\section{Changes of fatty acid synthesis-related gene expression in BA fruit}


Six genes involved in fatty acid biosynthesis were significantly regulated induced by BA. These genes included two malonyl CoA-acyl carrier protein transacylase genes (LOC103945733 and LOC103935263), a 3-oxoacyl-[acyl-carrier-protein] synthase gene (LOC103951262), a 3-hydroxyacyl-[acyl-carrier-protein] dehydratase gene (LOC103967963) and three enoyl-[acyl-carrier-protein] reductase genes (LOC103964860, LOC103959004 and LOC103940555) (Table 3).

\begin{tabular}{|lll|}
\hline \multicolumn{2}{|c|}{$\begin{array}{c}\text { Table 3 } \\
\text { List of DEGs relate to fatty acid biosynthesis }\end{array}$} \\
\hline ID & Gene description & $\log _{2}{ }^{\text {Fold Change }}$ \\
\hline Fatty acid biosynthesis & & \\
\hline LOC103945733 & Malonyl CoA-acyl carrier protein transacylase & 1.50 \\
\hline LOC103935263 & Malonyl CoA-acyl carrier protein transacylase & 1.35 \\
\hline LOC103951262 & 3-oxoacyl-[acyl-carrier-protein] synthase & 1.23 \\
\hline LOC103967963 & 3-hydroxyacyl-[acyl-carrier-protein] dehydratase & 1.40 \\
\hline LOC103964860 & Enoyl-[acyl-carrier-protein] reductase & 1.83 \\
\hline LOC103959004 & Enoyl-[acyl-carrier-protein] reductase & 2.43 \\
\hline LOC103940555 & Enoyl-[acyl-carrier-protein] reductase & 1.61 \\
\hline
\end{tabular}

\section{Changes of plant hormone metabolism-related gene expression in BA fruit}

Analysis of DEGs found that two indole-3-acetaldehyde oxidase genes (LOC103958137 and LOC103929079) and six Peroxidase genes (LOC103948174, LOC103951047, LOC103934752, LOC103964015, LOC103958862 and LOC103953577) which involved in IAA synthesis and degradation, respectively, were significantly down-regulated and up-regulated in BA fruit. Moreover, the expression levels of two GA synthesis genes (LOC108865311, LOC103948777 and LOC103939254) were significantly increased in BA fruit. Four key genes of ethylene synthesis (LOC103948231, LOC103943975 and LOC103939367) were significantly decreased in BA fruit (Table 4). 


\section{Table 4}

List of DEGs relate to plant hormone metabolism

ID

Gene description

$\log _{2}$ Fold Change

IAA degradation

LOC103958137 indole-3-acetaldehyde oxidase $\quad-4.93$

$\begin{array}{lll}\text { LOC103929079 indole-3-acetaldehyde oxidase } & -4.50\end{array}$

$\begin{array}{lll}\text { LOC103948174 Peroxidase, POD } & 1.60\end{array}$

$\begin{array}{lll}\text { LOC103951047 Peroxidase, POD } & 6.54\end{array}$

$\begin{array}{lll}\text { LOC103934752 Peroxidase, POD } & 2.43\end{array}$

$\begin{array}{lll}\text { LOC103964015 Pexidase, POD } & 3.11\end{array}$

$\begin{array}{lll}\text { LOC103958862 Peroxidase, POD } & 1.80\end{array}$

$\begin{array}{lll}\text { LOC103953577 } & \text { Peroxidase, POD }\end{array}$

GA synthesis

$\begin{array}{lll}\text { LOC108865311 ent-kaurene oxidase, KO } & 3.90\end{array}$

$\begin{array}{lll}\text { LOC103948777 ent-kaurenoic acid oxidase, KAO } & 1.81\end{array}$

LOC103939254 ent-kaurenoic acid oxidase, KAO 3.83

Ethylene synthesis

LOC103948231 1-aminocyclopropane-1-carboxylate oxidase, ACO $\quad-7.01$

LOC103943975 1-aminocyclopropane-1-carboxylate oxidase, ACO $\quad$-9.88

LOC103939367 1-aminocyclopropane-1-carboxylate oxidase, ACO $\quad-1.74$

LOC103956316 1-aminocyclopropane-1-carboxylate synthase, ACS $\quad-2.39$

\section{Discussion}

Many studies discovered that watercored had a consistently higher sorbitol content than healthy fruit in both apples and pears ${ }^{2}$. Moreover, Chun and our research also found the 'Akibae' is high-sucrose cultivar and the watercore fruit accumulated higher sucrose content 4,14 . Thus, the accumulation of sorbitol and sucrose has been speculated to be closely related to watercore. In pear production, it is commonly utilized from foliar applications of calcium at preharvest period ${ }^{15}$. However, the relationship between calcium concentration and watercore occurrence is not always apparent and in some cases is contradicted ${ }^{2}$. Boron is imperative element for plant growth and it must be obtainable in adequate quantities for optimal 
plant growth and productivity ${ }^{16}$. In this study, the sorbitol metabolism-related and sucrose metabolismrelated genes were significantly induced by BA which suggested that spraying boron during fruit development can reduce the occurrence of watercore by reducing sorbitol and sucrose accumulation. Moreover, boron has also been shown to form a stable complex with sorbitol and sucrose ${ }^{17,18}$. Although the function of boron in apple and pear remains unknown, it is becoming increasingly important to understand the significance of the formation of sorbitol-boron or sucrose-boron complexes in watercore development.

Pear starch in fruit started accumulating early and reached a maximum concentration during the middle phase of fruit development then decreased ${ }^{19}$. In this study, BA significantly increased the expression of $\beta$-amylase and accelerated starch degradation which promoted the formation of fruit quality. In addition, fruit aromas consist of many aroma volatiles, and fatty acid metabolism is an important metabolic pathway involved in the biosynthesis of aroma volatiles in fruit ${ }^{20}$. Previous study found application of boron led to a better olive oil quality by improving fatty acid composition ${ }^{21}$. In this study, BA also significantly induced the gene expression of fatty acid biosynthesis which indicated BA increase the formation of fruit aromas.

Boron affect the formation of fruit quality by regulating plant hormone metabolism. Hegazi found IAA and abscisic acid (ABA) decreased and GA increased in response to boron treatments which indicated a balance in endogenous hormones (IAA, GA, $A B A$ ) concentrations in olive tree has induced the maximum fruit set and yield ${ }^{22}$. Islam found the $\mathrm{Si}+\mathrm{B}$ treatment resulted in the lowest respiration and ethylene production ${ }^{23}$. In current study, BA significantly increased the expression of GA synthesis genes and inhibit the synthesis of ethylene and IAA which closely related to fruit size and delayed fruit softening.

Above all, we speculated a model which BA influence pear watercore occurrence and fruit quality (Fig. 6). The boron signal induced the decrease of sorbitol and sucrose synthesis gene expression or increase of gene expression of sorbitol transport, sorbitol degradation and sucrose degradation in pulp cells, resulting in the accumulation less sorbitol and sucrose in pulp and inhibited fruit watercored. Moreover, boron also affect the fruit aromas related genes and the balance of endogenous hormones which lead to the fruit internal and external quality. Hence, this study provided further information for understanding the molecular mechanisms of the influence of BA on pear.

\section{Declarations}

\section{Acknowledgements}

This work was supported by National Natural Science Foundation of China (No. 32001983) and Natural Science Foundation of Jiangsu Province (BK20200934).

\section{Author contributions}


$\mathrm{XL}$, JW and C-L W conceived and designed the research. DH L, YS and JL analyzed the data and performed the bioinformatics analysis. XL wrote the manuscript.

\section{Compliance with ethical standards}

\section{Conflict of interest}

The authors assure that the manuscript has not been submitted for publication elsewhere. All the authors have contributed equally to this article, and all have agreed to submit it for publication in this journal. All the authors declare that there are no conflicts of interest to disclose.

\section{Research involving human participants and/or animals}

This research is about transcriptomic analysis in plant (pear). Human participants/animals were not involved in this study.

\section{Informed consent}

Not applicable in this study.

\section{References}

1. Nishitani C, Inoue E, Saito T, Ogata N, Kita K, Gonai T, Kasumi M, Ishii R, Sawamura Y, Takada N, Nakamura Y, Kobayashi M, Yano K, Terakami S, Yamamoto T (2020) Transcriptome analysis of watercore in Pyrus pyrifolia by comparing pairs of susceptible and resistant F1 sibs. Sci Hortic 264. doi:10.1016/j.scienta.2019.109136

2. Itai A (2015) Watercore in Fruits, vol, 10: Abiotic stress biology in horticultural plants. Springer, Japan

3. Brdar-Jokanovic M (2020) Boron toxicity and deficiency in agricultural plants. Int J Mol Sci 21. doi:10.3390/ijms21041424

4. Liu X, Fan HM, Liu DH, Liu J, Shen Y, Zhang J, Wei J, Wang CL (2021) Transcriptome and metabolome analyses provide insights into the watercore disorder on "akibae" pear fruit. Int J Mol Sci 22. doi:10.3390/ijms 22094911

5. Feng SD (2017) Study on the characteristics of disease and control of bitter pit and watercore in pear trees. Yangzhou Univ, MA, Diss

6. Liu X, Zhang JW, Guo LX, Liu YZ, Jin LF, Hussain SB, Du W, Deng Z, Peng SA (2017) Transcriptome changes associated with boron deficiency in leaves of two citrus scion-rootstock combinations. 
Front Plant Sci 8. doi:10.3389/fpls.2017.00317

7. Silva AP, Rosa E, Haneklaus SH (2003) Influence of foliar boron application on fruit set and yield of hazelnut. J Plant Nutr 26:561-569. doi:10.1081/pln-120017665

8. Shaban AE, Ei-Motaium RA, Badawy SH, Ibrahim AS (2017) Improvement of mango (Mangifera indica L.) fruit quality and yield using boron foliar application. Bioscience Research 14:478-484

9. Nasirpour M, Khoshghalb H, Nemati H, Ramezani M, Rahimi M (2018) Foliar application of humic acid, calcium and boron on chemical characteristics and fruit quality of tomato. Agricultural Biological Research 34:1-15

10. Giacobbo CL, Picolotto L, Pasa MS, Fachinello JC (2018) Boron foliar application, branch girdling and plant growth regulators on yield and fruit quality of 'Garber' pear trees. An Acad Bras Cienc 90:1815-1822. doi:10.1590/0001-3765201820170106

11. Asgharzade A, Valizade GA, Babaeian M (2012) Investigating the effect of boron spray on yield nutrient content, texture and brix index of apple (Sheikh Amir Variety) in Shirvan region. Afr J Microbiol Res 6:2682-2685. doi:10.5897/ajmr11.1163

12. Ali M, Ahmad M, Anjam N, Hafeez ur R, Kasana MI, Tariq S, Ramzan A (2014) Efficacy of boron \& gibberellic acid on growth and fruit yield in olive (olea europaea L.) CV. gemlik. Int J Bio Biotech $11: 295-298$

13. Wu J, Wang Z, Shi Z, Zhang S, Ming R, Zhu S, Khan MA, Tao S, Korban SS, Wang H, Chen NJ, Nishio T, Xu X, Cong L, Qi K, Huang X, Wang Y, Zhao X, Wu J, Deng C, Gou C, Zhou W, Yin H, Qin G, Sha Y, Tao Y, Chen H, Yang Y, Song Y, Zhan D, Wang J, Li L, Dai M, Gu C, Wang Y, Shi D, Wang X, Zhang H, Zeng L, Zheng D, Wang C, Chen M, Wang G, Xie L, Sovero V, Sha S, Huang W, Zhang S, Zhang M, Sun J, Xu L, Li Y, Liu X, Li Q, Shen J, Wang J, Paull RE, Bennetzen JL, Wang J, Zhang S (2013) The genome of the pear (Pyrus bretschneideri Rehd.). Genome Res 23:396-408.

doi:10.1101/gr.144311.112

14. Chun JP, Tamura F, Tanabe K, Itai A (2003) Physiological and chemical changes associated with watercore development induced by GA in Japanese pear 'Akibae' and 'Housui'. J Jpn Soc Hortic Sci $72: 378-384$

15. Inomata Y, Yaegaki H, Suzuki K (1999) The effects of polyethylene bagging, calcium carbonate treatment and difference in fruit-air temperatures on the occurrence of watercore in Japanese pear 'Housui'. J Jpn Soc Hortic Sci 68:336-342

16. Kok D, Bal E (2019) Physical and biochemical properties of cv. michele palieri table grape ( $\mathrm{V}$. vinifera L.) in relation to various doses of foliar applications of oak and boron. Erwerbs-Obstbau 61:1-7. doi:10.1007/s10341-019-00432-6

17. Susidarti RA, Utomo RY, Qodria L, Ramadani RD, Ohta Y, Hattori Y, Kirihata M, Meiyanto E (2019) Preparation of pentagamaboronon-0 and its fructose and sorbitol complexes as boron carrier for boron neutron capture therapy (BNCT) application. Research in Pharmaceutical Sciences 14:286292. doi:10.4103/1735-5362.263552 
18. Du W, Pan ZY, Hussain SB, Han ZX, Peng SA, Liu YZ (2020) Foliar supplied boron can be transported to roots as a boron-sucrose complex via phloem in citrus trees. Front Plant Sci 11. doi:10.3389/fpls.2020.00250

19. Mesa K, Serra S, Masia A, Gagliardi F, Bucci D, Musacchi S (2016) Seasonal trends of starch and soluble carbohydrates in fruits and leaves of 'Abbe Fetel' pear trees and their relationship to fruit quality parameters. Sci Hortic 211:60-69. doi:10.1016/j.scienta.2016.08.008

20. Qin G, Tao S, Zhang H, Huang W, Wu J, Xu Y, Zhang S (2014) Evolution of the aroma volatiles of pear fruits supplemented with fatty acid metabolic precursors. Molecules 19:20183-20196. doi:10.3390/molecules 191220183

21. Toker $\mathrm{C}$, Yavuz $\mathrm{N}$ (2015) The effect of boron application on chemical characterization and volatile compounds of virgin olive oil of ayvalik olive cultivar. J Am Oil Chem Soc 92:1421-1428. doi:10.1007/s11746-015-2703-7

22. Hegazi ES, El-Motaium RA, Yehia TA, Hashim ME (2018) Effect of foliar boron application on boron, chlorophyll, phenol, sugars and hormones concentration of olive (Olea europaea L.) buds, leaves, and fruits. J Plant Nutr 41:749-765. doi:10.1080/01904167.2018.1425438

23. Islam MZ, Mele MA, Choi KY, Kang HM (2018) The effect of silicon and boron foliar application on the quality and shelf life of cherry tomatoes. Zemdirbyste 105:159-164. doi:10.13080/za.2018.105.020

\section{Figures}

A

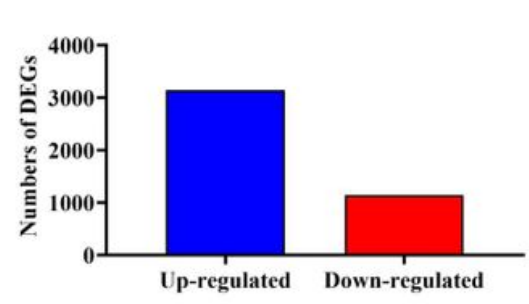

B

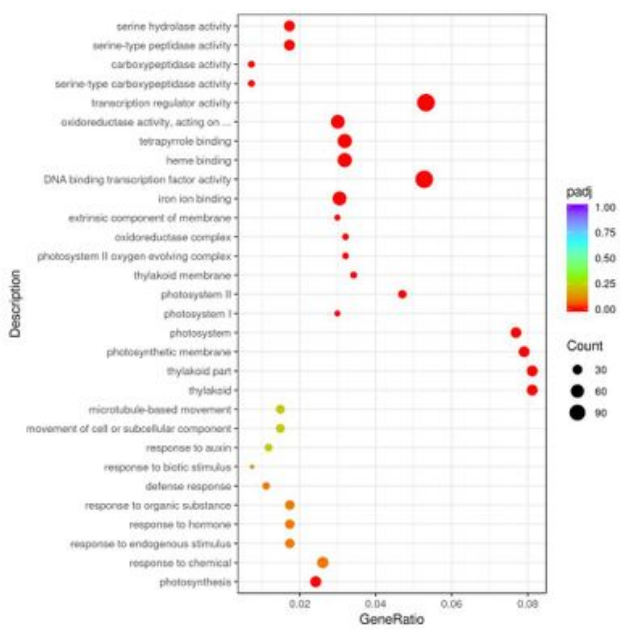

C

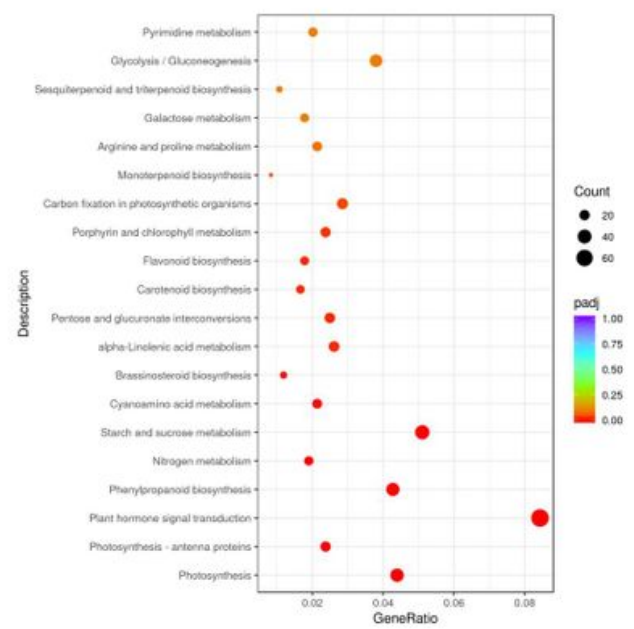


Figure 1

Number of DEGs (A), GO classification (B) and KEGG enrichment (C) of DEGs.

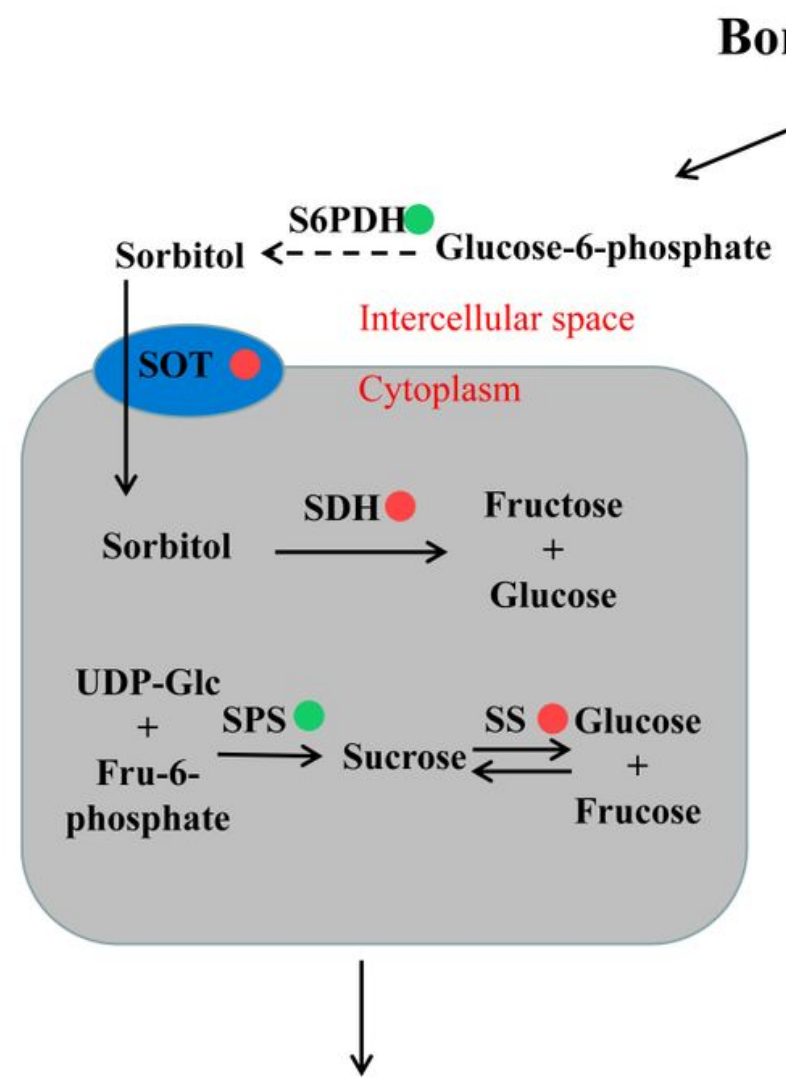

Alleviate the ccurrence of watercore
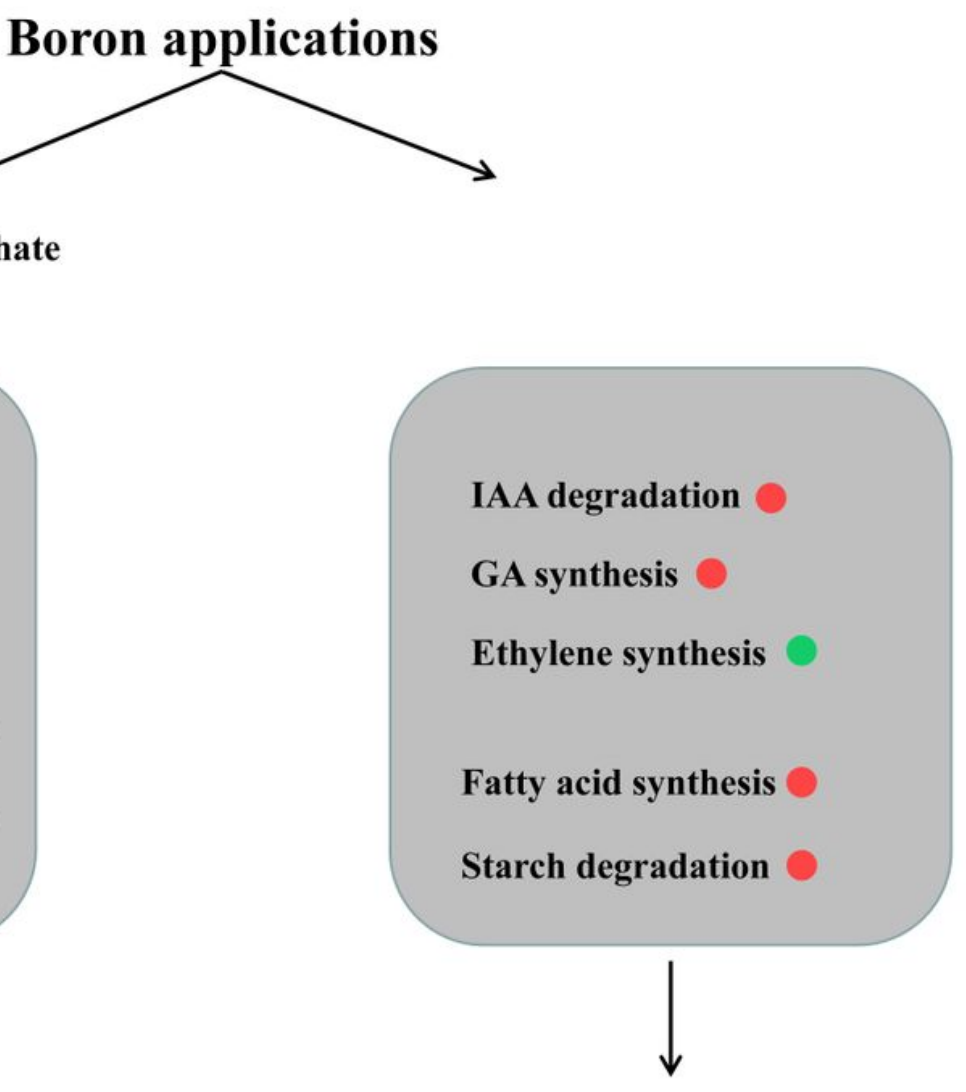

Promote fruit expansion and quality formation

\section{Figure 2}

A proposed model of BA influence on pear watercore occurrence and fruit quality. The red and green circle refers to promote and inhibit related gene expression or metabolic pathways, respectively. 